\title{
Review
}

\section{Nurturing brain plasticity: impact of environmental enrichment}

\author{
L Baroncelli ${ }^{\star 1,4}$, C Braschi ${ }^{2,4}$, M Spolidoro ${ }^{1,4}$, T Begenisic $^{1}$, A Sale ${ }^{3}$ and L Maffei ${ }^{1,3}$
}

Environmental enrichment (EE) is known to profoundly affect the central nervous system (CNS) at the functional, anatomical and molecular level, both during the critical period and during adulthood. Recent studies focusing on the visual system have shown that these effects are associated with the recruitment of previously unsuspected neural plasticity processes. At early stages of brain development, EE triggers a marked acceleration in the maturation of the visual system, with maternal behaviour acting as a fundamental mediator of the enriched experience in both the foetus and the newborn. In adult brain, EE enhances plasticity in the cerebral cortex, allowing the recovery of visual functions in amblyopic animals. The molecular substrate of the effects of EE on brain plasticity is multi-factorial, with reduced intracerebral inhibition, enhanced neurotrophin expression and epigenetic changes at the level of chromatin structure. These findings shed new light on the potential of EE as a non-invasive strategy to ameliorate deficits in the development of the CNS and to treat neurological disorders.

Cell Death and Differentiation (2010) 17, 1092-1103; doi:10.1038/cdd.2009.193; published online 18 December 2009

Adult brain architecture is the result of a complex interaction between genetic developmental programmes and experiencedriven plasticity processes. ${ }^{1,2}$ A large number of studies demonstrated the existence of time windows in early postnatal life, named critical periods (CPs), during which neural circuits display a heightened sensitivity to acquire instructive and adaptive signals from the external environment. Various brain regions subserving major behavioural functions (e.g., sensory perception, motor control and language) have CPs that occur at different times and are activated and regulated by distinct mechanisms. ${ }^{3,4}$

The primary visual cortex (V1) is a paradigmatic model for studying experience-dependent plasticity. Although the maturation of the visual system starts before eye opening and the initial targeting of neural connections is subjected to either genetic programmes or spontaneous activity, a proper development of the visual system requires sensory experience. ${ }^{5,6} \mathrm{~A}$ total absence of sensory input leads to a delay in the functional and anatomical maturation of the visual cortex, which appears immature far beyond the end of the critical period. Adult animals reared in darkness from birth (dark rearing, DR) display serious physiological deficits in their visual cortex, including reduced orientation and direction tuning, lower cell responsiveness, larger receptive field sizes, altered spontaneous activity, immature ocular dominance (OD) distribution and lower visual acuity (VA).$^{7-10}$

Ocular dominance plasticity refers to the rapid change in visual cortex physiology resulting from unbalanced inputs from the two eyes. Hubel and Wiesel ${ }^{11,12}$ first reported in kittens that reducing input from one eye by lid suture (monocular deprivation, MD) during development dramatically affects the binocularity of $\mathrm{V} 1$, leading to a loss of cortical responses to that eye and an increase in the number of neurons preferentially driven by the open eye. As a direct consequence, the deprived eye becomes amblyopic: its VA is strongly reduced and its contrast sensitivity is blunted. The effects of $\mathrm{MD}$ and the existence of a CP have been subsequently described in other species of mammals as well, including primates, ${ }^{13}$ rabbits, ${ }^{14}$ hamsters, ${ }^{15}$ rats, ${ }^{10}$ mice ${ }^{16}$ and ferrets. ${ }^{17}$

In parallel to experiments based on protocols of reduced or altered sensory experience, relevant progress in understanding the influence of environmental experience on the development, refinement and maintenance of appropriate neural

\footnotetext{
${ }^{1}$ Laboratory of Neurobiology, Scuola Normale Superiore, Pisa I-56100, Italy; ${ }^{2}$ Department of Psychology, Florence University, Florence I-50100, Italy and ${ }^{3}$ Institute of Neuroscience CNR, Pisa l-56100, Italy

*Corresponding author: L Baroncelli, Laboratory of Neurobiology, Scuola Normale Superiore, c/o Institute of Neuroscience, CNR, via Moruzzi 1, Pisa I-56100, Italy. Tel: + 390503 153190; Fax: + 390503 153220; E-mail: I.baroncelli@ sns.it.

${ }^{4}$ These authors contributed equally to this work.

Keywords: environmental enrichment; plasticity; visual system; maternal care; neurological disorders

Abbreviations: 5-HT, 5-hydroxytryptamine; A1, primary auditory cortex; AD, Alzheimer disease; NGF, nerve growth factor; APP, amyloid precursor protein; AMPA, $\alpha$-amino-3-hydroxyl-5-methyl-4-isoxazole-propionate; APOE, apolipoprotein E; BACE, $\beta$-site APP-cleaving enzyme; BDNF, brain-derived neurotrophic factor; BFCN, basal forebrain cholinergic neurons; CaMKII, Ca2 + /calmodulin-dependent protein kinase II; RT-PCR, real-time polymerase chain reaction; CNS, central nervous system; CP, critical period; CRE, CAMP response element; $C R E B$, CAMP response element binding; CSPG, chondroitin-sulfate proteoglycans; DR, dark rearing; DS, Down syndrome; Chr, chromosome; EE, environmental enrichment; GABA, $\gamma$-aminobutyric acid; GAD65, glutamic acid decarboxylase 65; IGF-I, insulin-like growth factor I; LTP, long-term potentiation; MD, monocular deprivation; NMDA, N-methyl-D-aspartic acid; EEG, electroencephalogram; NT-3, neurotrophin-3; OD, ocular dominance; VA, visual acuity; PNN, perineuronal net; PS1/2, presenilin 1/2; ReS, Rett sindrome; MeCP2, methyl-CpG binding protein; RGC, retinal ganglion cell; SOD1/2, superoxide dismutase 1/2; V1, primary visual cortex; VEGF, vascular endothelial growth factor; VEP, visual evoked potential; WM-LTP, white-matter long-term potentiation

Received 08.7.09; revised 16.10.09; accepted 16.10.09; Edited by RA Knight; published online 18.12 .09
} 


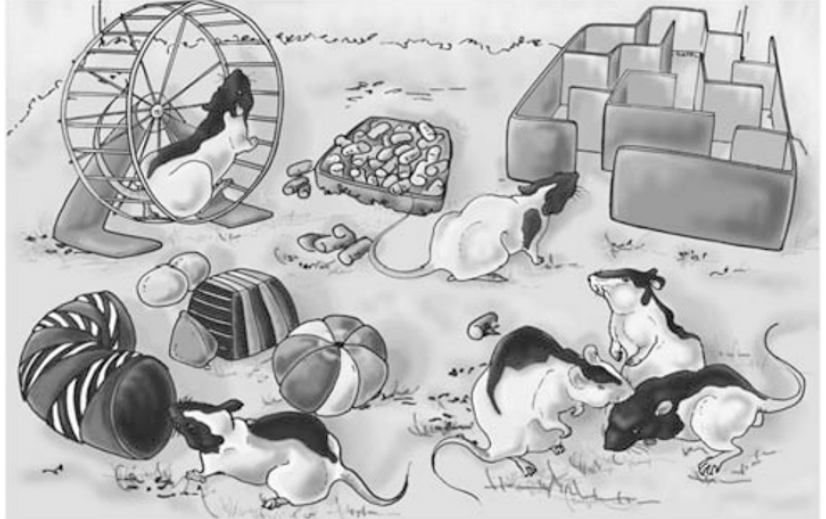

Figure 1 Environmental enrichment (EE) is a manipulation of the standard laboratory conditions that modify the quality and intensity of environmental stimulation, reaching an optimization of the rearing environment. The goal of EE is to provide animals with increased levels of multisensory stimulation, physical activity and social interactions, and by eliciting spontaneous explorative behaviours. Drawing by M. Marchi

connections has been made possible by paradigms specifically devoted to increasing the quality and intensity of environmental stimulation, such as environmental enrichment (EE). EE is defined as 'a combination of complex inanimate and social stimulation'. ${ }^{18}$ Enriched animals are reared in large groups and housed in widely stimulating environments in which a variety of differently shaped objects are present and changed frequently. The goal of EE is to improve the animals' quality of life by providing them with a combination of multisensory/cognitive stimulation, increased physical activity, enhanced social interactions and by eliciting natural explorative behaviours (Figure 1). Hence, in contrast to the approaches based on sensory deprivation, EE is a gain-offunction paradigm allowing the study of the influence elicited by increased levels of environmental stimulation on brain development and plasticity.

Environmental enrichment exerts profound effects on the adult central nervous system (CNS). A large number of studies highlighted the fact that EE modifies the behaviour of animals, leading to a sensitive improvement in complex cognitive functions, particularly learning and memory, ${ }^{19}$ and positively affecting the animal's emotional and stress reactivity. ${ }^{20}$ Rodents living in EE conditions display increased levels of hippocampal long-term potentiation (LTP), a physiological model of synaptic plasticity related to learning and memory. ${ }^{21}$ This functional improvement is accompanied by prominent changes at the anatomical level, with robust increments in cortical thickness and weight and modifications of neuronal morphology, in terms of increased dendritic arborization, number of dendritic spines, synaptic density and postsynaptic thickening, occurring in several regions of the brain, particularly in the occipital cortex and hippocampus. ${ }^{22}$ Moreover, exposure to EE increases hippocampal neurogenesis and the integration of newly born cells into functional circuits. $^{21}$ At the molecular level, EE causes a significant change in the expression of a large set of genes involved in neuronal structure, excitability, synaptic transmission and plasticity, ${ }^{23}$ modulating the synthesis and secretion of neurotrophic factors throughout the brain and affecting the cholinergic, serotoninergic and noradrenergic systems. ${ }^{24-27}$
Although EE research has been mostly focused on rodents, similar effects have been reported in several species of mammals (gerbils, ground squirrels, rabbits, cats and primates). ${ }^{28-32}$

\section{Influence of EE on Brain Developmental Plasticity}

Despite the large body of evidence with regard to the effects of EE on the adult brain, until recently, the influence of EE on the developmental physiology and plasticity of the CNS has remained only scarcely investigated. In the past few years, this gap has been considerably filled with a series of studies focusing on the visual system as a paradigmatic model. The most relevant result was the demonstration that EE from birth induces a marked acceleration in the maturation of VA, an effect consistently reported in mice and rats using both electrophysiological and behavioural methods. ${ }^{33-36}$ The acceleration effect is quite strong, yielding a 1-week advance in the time course of VA maturation with respect to control animals. This functional outcome is accompanied by a precocious decline in the possibility of inducing LTP of layer II-III field potentials after theta-burst stimulation of the white matter (WM-LTP) in the visual cortex, ${ }^{34}$ a well-established in vitro model of developmental plasticity. ${ }^{37} \mathrm{EE}$ also promotes visual system maturation in the absence of visual experience, with DR rats maintained in EE conditions showing a normal VA development and closure of the CP for OD plasticity. ${ }^{38}$ This indicates that non-visual stimulation counteracts the effects exerted by a complete lack of visual experience from birth. In the auditory system, pre-weaning EE improves spatial localization abilities and enhances directional sensitivity of $A 1$ neurons, ${ }^{39}$ whereas it remains unexplored whether exposure to $E E$ conditions induces compensation for the delay in A1 maturation prompted by white noise rearing.

It is worth noting that rearing animals in EE during their early phases of life leads to a functional phenotype very similar to that previously reported in transgenic mice overexpressing BDNF in the forebrain. ${ }^{40,41}$ Indeed, mice raised in EE show increased levels of the BDNF protein in their visual cortex at $\mathrm{P} 7,{ }^{34,35}$ revealing the fact that neurotrophin BDNF is one of the crucial factors that underlie EE effects on V1 maturation. In both BDNF overexpressing mice and EE pups, higher BDNF levels were also shown to trigger the maturation of the inhibitory GABAergic system, which, by affecting receptive field development and synaptic plasticity, could determine both the accelerated maturation of VA and the decline of cortical plasticity. ${ }^{34,35,40}$

Another molecular factor involved in mediating EE effects on visual system development is IGF-I. ${ }^{42}$ IGF-I expression is higher at $\mathrm{P} 18$ in the visual cortex of $\mathrm{EE}$ rats compared with non-EE rats. Moreover, exogenous IGF-I supply mimics, whereas blocking IGF-I action prevents the EE effects on VA maturation. The authors observed that inhibitory interneurons respond to IGF-1 with a GAD65 increase in their synaptic terminals, suggesting that a possible explanation for the effects of IGF-I on VA development could be an action on the inhibitory GABAergic system. ${ }^{42}$

BDNF and IGF-I signalling may eventually converge on the activation of intracellular pathways, leading to the phosphorylation of the transcription factor CREB. The wave of CREB/ CRE-mediated gene expression in the visual cortex is 
accelerated in EE mice, and chronic injections of non-EE animals with rolipram, a pharmacological treatment increasing the phosphorylation of CREB, partially mimic the EE outcome on VA maturation. ${ }^{34}$ Thus, activation of the CREB/ CRE transcription pathway may be one crucial mediator of the EE effects on visual system development.

Retina development is also affected by high levels of environmental stimulation. It has been recently reported that DR induces alterations in both the anatomical stratifications of retinal ganglion cells (RGCs) and the visual responsiveness of inner retinal neurons. ${ }^{43,44} \mathrm{EE}$ accelerates the segregation of RGC dendrites into ON and OFF sublaminae, ${ }^{36}$ as well as the rise of retinal acuity during development, even in animals exposed to differential rearing before eye opening, for the first 10 days of life. ${ }^{45}$ IGF-I and BDNF are key molecular factors in these processes: retinal levels of both proteins are precociously increased in the RGC layer of developing EE rats, and blocking either IGF-I or BDNF action in EE animals counteracts the faster retinal maturation. ${ }^{36,45,46}$ BDNF turned out to be a downstream target of IGF-I. ${ }^{46}$

Strikingly, the maturation of the nervous system is sensitive to environmental stimulation during prenatal life as well. Recent data by Sale et al. ${ }^{47}$ demonstrated that exposing pregnant females to EE (maternal enrichment) profoundly affects the development of the retina in embryos, leading to an acceleration of structural processes critical for retinal maturation, such as the migration of neural progenitors and the time course of naturally occurring cell death in the RGC layer. Interestingly, a key factor in the effects of maternal enrichment on retinal morphology and function is IGF-I. Anatomical modifications are indeed accompanied by a marked increase in IGF-I levels in the retinas of EE pups and in maternal milk. Furthermore, IGF-I infusion during late pregnancy is sufficient to induce, in non-EE animals, all the reported changes elicited by $E E$ in foetuses, whereas neutralization of IGF-I in EE mothers prevents the action of maternal enrichment on retinal development. $^{47}$

The influence of increased maternal stimulation during pregnancy is not only restricted to the visual system. Voluntary wheel running of pregnant mice leads to a twofold increase in hippocampal precursor-cell proliferation in their pups. ${ }^{48}$ Maternal physical activity in the form of swimming during pregnancy has also been shown to increase hippocampal BDNF mRNA expression in the offspring leading to improved short-term memory abilities. ${ }^{49}$

\section{Maternal Care, Tactile Stimulation and Visual System Development}

The aforementioned studies demonstrate that, far from being rigidly determined by genetic programmes, CNS development is already responsive to the environment at very early stages. The first two weeks of rodent life are characterized by the prevalent absence of a direct interaction between the pup and the external environment, with newborns spending their whole time in the nest, where the mother is the most important source of sensory experience. ${ }^{50}$ It was soon realized that differences in maternal behaviour between EE and non-EE conditions could be a fundamental factor triggering the earliest effects of $E E$ on visual system development. This issue has been directly addressed by a detailed quantitative study of maternal behaviour in different environmental conditions, which led to the first demonstration that EE pups receive higher levels of maternal care compared with standard-reared pups. ${ }^{35}$ More specifically, EE animals experience a continuous physical contact because of the presence of adult females in the nest and are also provided with increased levels of licking and grooming (Figure 2a). The amount of maternal care received by the developing pup influences hippocampal structure and function, affects molecular factors crucial for plasticity such as BDNF and NMDA receptors and leaves long-lasting epigenetic marks in the offspring's physiology and behaviour. ${ }^{50-53}$

Very recently, a protocol of daily artificial tactile stimulation has been used in the rat as a strategy to promote visual system development. ${ }^{54}$ The authors reported that a combination of gently stroking and massaging is highly effective in accelerating the maturation of physiological visual functions, in particular of VA (Figure 2b). Interestingly, tactile stimulation increases IGF-I levels in the visual cortex at P18, as also observed in EE animals, and blocking IGF-I action prevents the effects of massage on VA development. ${ }^{54}$ Tactile stimulation also compensates for inadequate maternal care: the negative effects produced by repeated episodes of maternal separation or by prenatal stress on pup growth, hormone secretion, hypothalamus-pituitary-adrenal axis and BDNF expression are all rescued by artificial massage applied to pups in order to mimic maternal behaviour. ${ }^{55-57}$ Altogether, these results provide a remarkable example of cross-modal plasticity by which an increased input in a single modality reverberates as a driving force for the whole brain.

Strikingly, Guzzetta et al. ${ }^{54}$ demonstrated that massage therapy also accelerates brain development in healthy preterm infants (gestational age between 30 and 33 weeks). The authors found that massaged infants exhibit an earlier shortening of the interbust intervals in the EEG, a robust index of the developmental stage of the brain, a significantly greater reduction in the latency of flash VEPs and an increase in behavioural VA outlasting the end of treatment (Figure 2c). In parallel to the results found in the animal model, massaged infants showed increased levels of plasma IGF-I, confirming that this molecule is crucially involved in mediating the effects of an enhanced sensory stimulation in the brain. ${ }^{54}$ This result is supported by the finding that, in preterm infants, tactile stimulation causes an increase in growth hormone production ${ }^{55}$ and an enhancement of serum IGF-I. ${ }^{58}$ Finally, very recent papers have shown that IGF-I and IGF-I binding protein 3 (IGFBP3) could be protective against proliferative retinopathy of prematurity, a severe and relatively frequent visual disorder in preterm infants. ${ }^{59,60}$ The paper by Guzzetta et al. ${ }^{54}$ underlines the role of environmental stimulation as a crucial factor for early postnatal development in humans. Massage therapy could be a good implementation of normal intensive treatment reserved for preterm babies aimed at more efficaciously counteracting the onset of neurological pathologies associated with a precocious delivery.

\section{Rejuvenating the Adult Brain}

A classical dogma in neuroscience is that brain plasticity undergoes a dramatic decline with age. Significant effort is being made in multiple laboratories to develop new strategies 

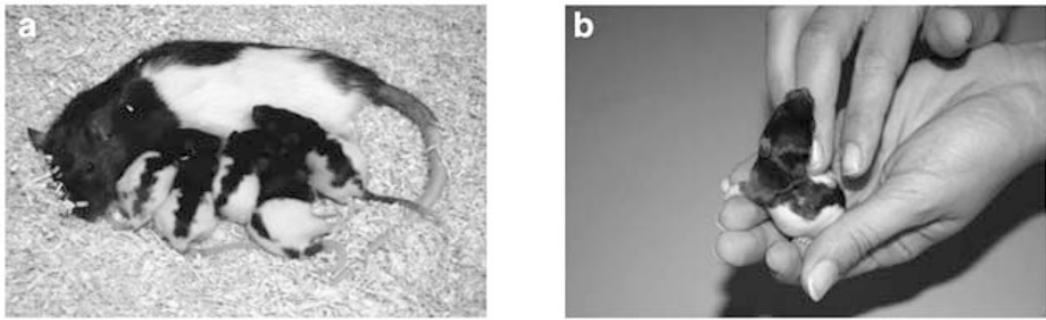

A1 Presence of adult females in the nest

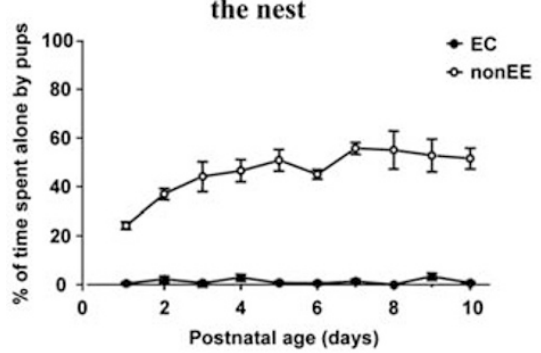

A2 Licking behaviour

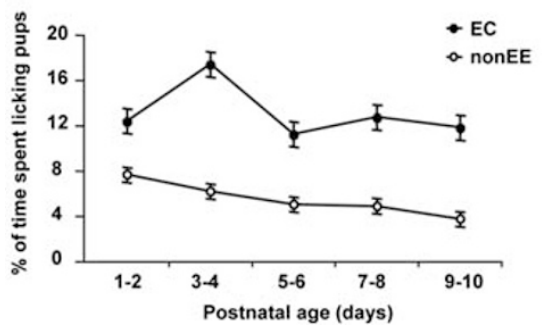

B VEP visual acuity
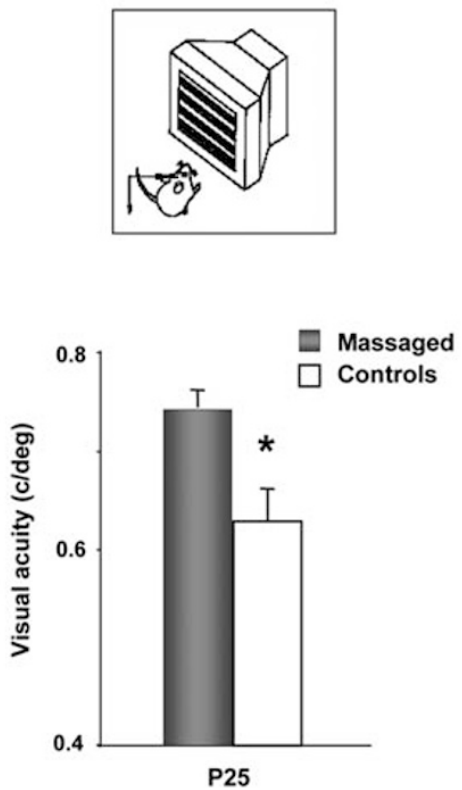

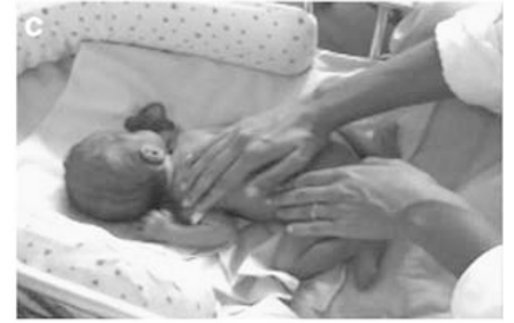

C Behavioural visual acuity

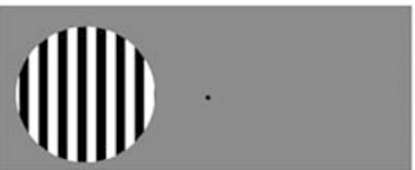

Two-alternative forced choice preferential looking test

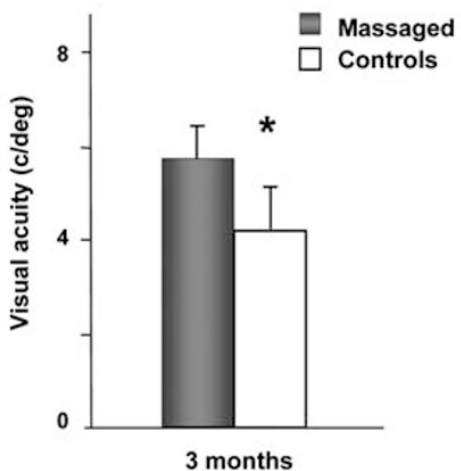

Figure 2 (a) Enriched pups experience higher levels of maternal care compared with standard-reared pups. (A1) The frequency of 'pups alone in the nest' recordings during the first 10 days postpartum in non-environmental enrichment $(\mathrm{EE})$ (white) and $\mathrm{EE}$ (black) animals. Two-way RM ANOVA revealed a significant effect of age and housing condition $(P<0.001)$ and a significant interaction between age and housing condition $(P<0.001)$. SNK post hoc analysis revealed that groups differ statistically $(P<0.05)$. Vertical bars are S.E.M. (A2) Frequency of 'licking' recordings during the first 10 days postpartum in non-EE (white) and EE (black) animals. Two-way RM ANOVA revealed a significant effect of age and housing condition $(P<0.001)$ and a significant interaction between age and housing condition $(P<0.05)$. SNK post hoc analysis revealed that groups were statistically different $(P<0.05)$. Vertical bars are S.E.M. Graphs have been modified from Sale et $a l^{35}(\mathbf{b})$ Massage in rat pups accelerates visual acuity maturation. The massage protocol combined gently stroking and massaging to mimic maternal care. Each animal received 5 min of tactile stimulation thrice a day: 2 min with a wet soft paintbrush on their back, head, limbs and abdomen to mimic licking; 1.5 min massage with finger tips on both sides of their back combined with passive gentle movement of their limbs; 1.5 min with a soft toothbrush on the back and abdomen to mimic grooming. (B1) Mean visual acuity determined at P25 by means of VEPs recorded from the primary visual cortex for massaged (grey) and control rats (white). The massage group significantly differs from the control group (one-way ANOVA, factor treatment significant, $P<0.05$, post hoc Holm-Sidak method). An asterisk denotes significant difference. Vertical bars are S.E.M. Graph has been modified from Guzzetta et al. ${ }^{54}$ (c) Maturation of the visual system is accelerated in massaged preterm infants. Massage therapy was begun on day 10 ( \pm 1 ) after birth. Sessions were performed thrice a day for two blocks of 5 days each, separated by a 2-day interval. Each treatment session consisted of $10 \mathrm{~min}$ of tactile stimulation, followed by $5 \mathrm{~min}$ of kinaesthetic stimulation. During tactile stimulation, the infant was placed prone and was given moderate pressure stroking with the flats of the fingers of both hands. Head, neck, shoulders, buttocks and both legs and arms were stimulated. For the kinaesthetic phase, the infant was placed in a supine position. Passive flexion/extension movements of the limbs in sequence were applied. (C1) Behavioural visual acuity measured by means of the Vital-Durand Acuity Cards at 3 months corrected age. Visual acuity in massaged infants is significantly higher than in controls at 3 months $(P<0.05, t$-test). Normal value for term-born infants at 3 months is $3-5.2 \mathrm{c} / \mathrm{deg}$. An asterisk denotes significant difference. Vertical bars are S.E.M. Graph has been modified from Guzzetta et al. ${ }^{54}$

aimed at enhancing CNS plasticity after the end of CP. In this fascinating field, the visual system emerges as the election test bed. Visual experience, indeed, can be easily controlled and the consequences of manipulations are readily measured at the anatomical, cellular and molecular level. From classic experiments in animal models to human clinical studies, it is well known that early abnormal visual experience owing to anisometropia (unequal refractive power in the two eyes), strabismus (abnormal alignment of one or both eyes), congenital cataract or, in animal models, $\mathrm{MD}$ results in a functional imbalance between the two eyes, leading to amblyopia, a widely diffused pathology (2-5\% incidence in the human population) for which no suitable treatment is yet available in the adult. ${ }^{61}$ Amblyopia causes a dramatic loss of VA in an apparently healthy eye, with a great deal of evidence showing that it also results in a broad range of other perceptual abnormalities, including deficits in stereopsis and contrast sensitivity. ${ }^{62,63}$ Similarly, in animal models, the classic hallmarks of amblyopia are a permanent loss of VA in the affected eye and a pronounced OD shift of visual cortical neurons in favour of the normal eye. ${ }^{64-68}$ Traditional amblyopia therapy consists of patching 
or penalizing the preferred fellow eye, thus forcing the brain to use the visual input carried by the weaker amblyopic eye. ${ }^{69}$

Although it is widely accepted that the reinstatement of visual functions is possible only if corrective therapy is started early in development, recent studies in rodents have unmasked a previously unsuspected potential for promoting recovery well after the end of CP (for a recent review, see Spolidoro et al. ${ }^{70}$ ). EE turned out to be very effective for treating amblyopia in adulthood. A brief exposure (2-3 weeks) of adult amblyopic rats to $E E$ has been demonstrated to promote a complete recovery of both VA and OD, an effect documented not only at the electrophysiological level but also by using behavioural assessments ${ }^{71}$ (Figure 3a). Recovery of plasticity in EE rats is associated with a threefold reduction in the basal levels of GABA detected in the visual cortex by in vivo brain microdialysis. As a consequence of decreased cortical inhibition, EE dynamically regulates cortical synaptic plasticity as well, resulting in a recovery of the possibility to evoke WM-LTP in visual cortical slices, ${ }^{71}$ a form of LTP that is normally occluded in adulthood as a result of the maturation of inhibitory circuits. ${ }^{37,40}$ The reduction of inhibition has proved to be a crucial molecular mechanism underlying the enhancement of plasticity induced by EE (Figure $3 b$ ), because restoration of plasticity is completely prevented by benzodiazepine cortical infusion during the EE period. ${ }^{71}$ The excitatory-inhibitory balance of cortical activity is well known to be crucially involved in regulating plasticity in the developing and adult brain. ${ }^{40,72}$ Consistently, chronic fluoxetine administration, another manipulation that reactivates cortical plasticity in adulthood promoting a full reinstatement of OD plasticity in response to MD and the recovery of visual functions from amblyopia, reduces GABAergic transmission, and its effects are prevented by enhancing inhibition with diazepam. ${ }^{73}$ There is also indirect evidence that the enhanced experience-dependent visual cortical plasticity driven by exposure of adult rats to complete darkness may also be related to a reduced expression of GABAA receptors relative to AMPA receptors, thus altering the balance between inhibition and excitation in the visual cortex. ${ }^{74,75}$
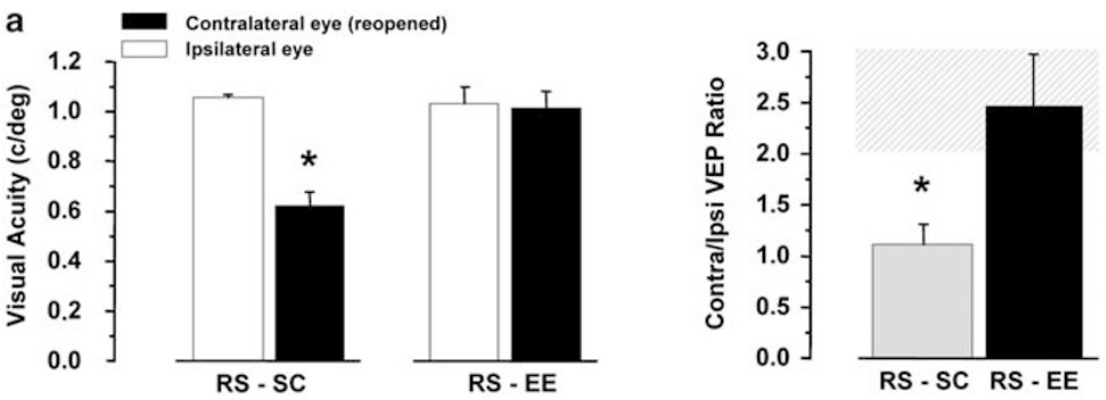

b

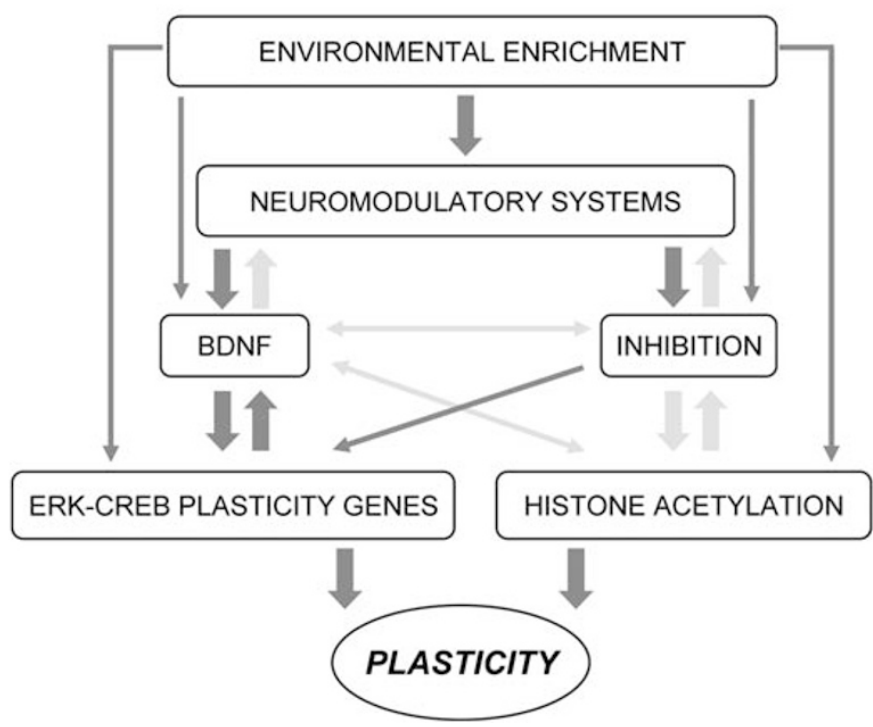

Figure 3 Experience-dependent reactivation of neural plasticity in the adult visual cortex. (a) EE in adulthood promotes visual acuity and binocularity recovery from amblyopia. Left: Behavioural and electrophysiological measurements of visual acuity of the two eyes revealed that the visual acuity of the amblyopic eye was significantly recovered in RS-EE (paired $t$-test, $P=0.864$ ), but not in RS rats raised in standard conditions (SC) (paired $t$-test, $P<0.05$ ). Right: The VEP ratio was statistically lower in RS-SC compared with RS-EE rats (t-test, $P<0.05)$, but did not differ between RS-EE and normal (not deprived) adult rats $(P=0.907)$. The hatched grey box represents the range of values for the VEP ratio in adult normal animals. Asterisks indicate statistical significance. Error bars represent S.E.M. Graphs have been modified from Sale et al..$^{71}$ (b) Schematic diagram showing key molecular events underlying restoration of plasticity in the adult visual system. We propose a model in which environmental stimulation could promote the strengthening of neuromodulatory transmission that triggers the decrease in GABA-mediated intracortical inhibition and, in parallel or in series, the enhancement of BDNF expression. Both the increase in overall cortical activity and BDNF intracellular signalling could in turn induce a transcriptional programme that leads to activation of other genes promoting plasticity, for instance through the ERK-CREB pathway. Furthermore, an influence on the epigenetic control of gene transcription has been suggested for EE. Dark grey arrows represent well-documented interactions between boxes; light grey arrows indicate likely interactions in the context of visual cortical plasticity, deserving further experimental characterization 
The promising results obtained with EE in rodents provide new hope for clinical application to human patients, given the completely non-invasive nature of this approach. Strikingly, an increasing number of clinical studies have reported that repetitive visual training based on sensory enrichment procedures may represent a very useful approach for the treatment of amblyopia, providing substantial improvement in a variety of visual tasks ${ }^{76-79}$ (for a review, see Polat ${ }^{80}$ and Levi and $\mathrm{Li}^{81}$ ). One caveat to the therapeutic value of these visual practice procedures, however, is the narrow specificity of achievable improvement, which is typically limited to the selected trained stimulus, condition or task. ${ }^{82}$ Only in a few tasks (Vernier acuity, contrast sensitivity and detection) did training lead, at least in some subjects, to a generalization of beneficial effects to other degraded visual functions, such as VA and stereoacuity. ${ }^{81}$ Interestingly, it has been suggested that the balance between excitation and inhibition is also impaired during development in amblyopic human subjects and that cortical overinhibition could underlie the degradation of spatial vision abilities. ${ }^{83-87}$

The study of experimental models of amblyopia has the advantage of enabling researchers to uncover new molecular mechanisms underlying the therapeutic value of the used procedures. The reduction of cortical inhibition in the visual cortex of EE rats is paralleled by an increased expression of BDNF $^{71}$ (Figure 3b), a neurotrophic factor critical for experience-dependent plasticity. ${ }^{40}$ Interestingly, it has been recently shown that intracortical administration of BDNF reactivates neural plasticity in the adult visual cortex ${ }^{73}$ and that TrkB signalling is required for the recovery of deprivedeye responses subsequent to the reinstatement of binocular vision during development. ${ }^{88} \mathrm{EE}$ also leads to increased levels of histone acetylation in the hippocampus and neocortex. ${ }^{89}$ A similar relationship between histone acetylation and EE effects could be present in the adult visual system (Figure 3b), in which pharmacological treatment with inhibitors of histone deacetylases restores OD plasticity. ${ }^{90}$ Another way by which EE can regulate gene expression might be the activation of specific transcription factors. One possibility is that BDNF intracellular signalling stimulates CREB phosphorylation and activation, ${ }^{91-93}$ which has a pivotal role in various forms of plasticity in the visual cortex ${ }^{94-96}$ and other brain structures. ${ }^{97}$ In line with this hypothesis, it has been shown that EE in adulthood increases immunoreactivity to CREB in the hippocampus as well ${ }^{98}$ (Figure $3 b$ ).

Moving from the intracellular environment to the extracellular milieu, one interesting observation is that EE in amblyopic rats reduces the density of chondroitin-sulphate proteoglycan (CSPG) perineuronal nets (PNNs) in the visual cortex. ${ }^{71}$ CSPGs exert a powerful repressive control on adult plasticity. This is demonstrated by pharmacological studies in which the removal of crucial components of PNNs from the mature extracellular matrix, by means of the enzyme chondroitinase $A B C$, reactivates $O D$ plasticity in monocularly deprived adult rats and promotes recovery from the effects of early visual deprivation on VA and binocularity of cortical neurons. ${ }^{99,100}$ These functional effects are accompanied by a recovery of dendritic-spine density, indicating that the removal of CSPGs favours remodelling of synaptic contacts onto visual-cortex pyramidal neurons. ${ }^{100}$
Thus, working with EE offers the opportunity to affect brain dysfunctions at multiple sites of action, either by allowing the replication of the successful outcome obtained with pharmacological treatment that is difficult to apply in humans or by indicating completely new ways of intervention.

The exact molecular modifications occurring upstream from the decrease in intracortical inhibition and the enhancement of BDNF expression observed in EE rats still need to be clarified. One appealing possibility is the involvement of neurotransmitter systems characterized by diffuse projections throughout the entire brain, which have been reported to profoundly affect plasticity in both the developing and adult brain. ${ }^{73,101}$ First studies by Rosenzweig et al. ${ }^{24,102}$ reported an increase in acetylcholinesterase activity, indicating an effect on the cholinergic system. Subsequent studies confirmed and extended this initial observation to other neurotransmitter systems, showing that EE increases noradrenaline concentration and strengthens the $\beta$-adrenoceptor signalling pathway in the cerebral cortex, cerebellum and brainstem, ${ }^{27,103}$ and augments mRNA expression levels of serotonin $1 \mathrm{~A}$ receptor and serotonin $(5-\mathrm{HT})$ concentration in the cerebral cortex and hippocampus. ${ }^{25,104,105}$ Interestingly, in vitro studies have repeatedly reported that $5-\mathrm{HT}$, acetylcholine, dopamine and, to a lesser extent, noradrenaline, suppress inhibition in several brain regions, including the visual cortex, possibly through a presynaptic mechanism mediated, respectively, by $5-\mathrm{HT}_{1 / 2}$, muscarinic $\mathrm{D} 1$ and the $\alpha$-adrenergic receptor families. ${ }^{106-113}$ Moreover, very recently, a modification of visual cortex pyramidal neuron responses to input signals depending on the behavioural state has been observed, related to a bidirectional modulation of somatic inhibition. ${ }^{114}$ Equally, a vast number of studies have shown that neuromodulators, and in particular 5- $\mathrm{HT}$, dramatically increase the expression of BDNF mRNA in the neocortex. ${ }^{115-118}$ These facts, together with the recent finding that fluoxetine administration leads to a reduced GABAergic neurotransmission and an increased BDNF expression in the visual cortex of adult rats, ${ }^{73}$ indicate that $5-\mathrm{HT}$ might act as an effective trigger of EE effects on adult cortical plasticity (Figure 3b). Interestingly, the neuromodulatory systems are known to regulate the arousal state of the brain ${ }^{101}$ and to modulate attentional processes. ${ }^{119-121} \mathrm{~A}$ recent study in nonamblyopic subjects provides indirect support to the important role of visual attention in driving visual cortex plasticity, showing that normal-sighted people trained with action-based video games have robust improvements in basic visual functions. ${ }^{122}$ The same effect was not observed after nonaction video game playing (equally engaging and visually complex, but operating at a slower pace and not requiring precise visually guided actions), suggesting that allocation of attention is a fundamental component for the effectiveness of the training paradigm. ${ }^{123,124}$

\section{Beyond the Sensory Cortex: EE Effects on Animal Models of Cognitive Impairment}

The encouraging results obtained using EE as a tool to modulate the development of the CNS and as a strategy to reopen plasticity windows in the adult have shown that it is possible to control processes crucial for brain function in a 
totally non-invasive manner. An important line of research deals with the potential therapeutic effects of EE in experimental models of nervous system injuries and disorders (for a comprehensive review, see Will et al. ${ }^{125}$ and Nithianantharajah and Hannan ${ }^{126}$ ). Given that the action of EE on brain plasticity is multi-factorial, reducing intracerebral inhibition, ${ }^{71}$ increasing histone acetylation ${ }^{89}$ and enhancing neurotrophin expression, ${ }^{26}$ it may be particularly efficacious in delaying the progression and/or in ameliorating the symptoms of those neurological disorders in which neuronal plasticity is compromised due to alterations in some or all of these processes. Here, we focus on Rett's syndrome, Down's syndrome and Alzheimer's disease.

Rett's syndrome. Rett's syndrome (ReS) is a progressive disorder of CNS development that predominantly affects the female population in early childhood. After a period of apparently normal development, the onset of developmental stasis and rapid deterioration occurs at 6-18 months of age, resulting in a complex neurological and neurobehavioural phenotype with mild-to-moderate mental retardation and severe dysfunction in motor coordination skills. ${ }^{127}$ ReS has been related to loss-of-function mutations in the X-linked gene encoding the methyl-CpG-binding protein (MeCP2) involved in the regulation of epigenetic mechanisms of gene expression. ${ }^{128}$ MeCP2 is a multi-functional protein having a key function in transcriptional silencing and activation ${ }^{129}$ and in the modulation of RNA splicing. ${ }^{130}$

Mice carrying conditional deletion or neuron-specific expression of mutated MeCP2 forms provide a very good model in which to examine behavioural and molecular mechanisms of ReS. ${ }^{131,132}$ These transgenic mice exhibit abnormalities in motor coordination, social interaction and cognitive abilities, with hemizygous males displaying the most severe phenotype. ${ }^{131-134}$ Electrophysiological studies from MeCP2 transgenic mice reported reduced neuronal activity in cortical $^{135}$ and hippocampal ${ }^{136}$ neurons, suggesting that a shift in the balance between inhibition and excitation could be responsible for rapid motor, behavioural and cognitive regression typical of ReS. ${ }^{137}$ MeCP2-deficient mice have attenuated ability to express LTP in the hippocampus ${ }^{136,138}$ and in the motor and somatosensory cortex. ${ }^{138}$

Importantly, the gene encoding BDNF is under MeCP2 regulation, ${ }^{139}$ and the progression of symptoms in MeCP2deficient mice seems to be correlated with gradually decreasing levels of circulating BDNF. ${ }^{140}$ Given that BDNF expression depends on neuronal activity, the reduced neuronal excitability caused by MeCP2 insufficiency could lead to a decreased BDNF protein level. ${ }^{140}$ BDNF overexpression in MeCP2 mutant mice is able to compensates the deficits at both the behavioural and electrophysiological level. ${ }^{140}$ This implies that neurons deficient in functional MeCP2 retain the capacity to recover when appropriate neurotrophic signalling is re-established. Similarly, motor coordination and cognitive deficits in MeCP2 mutant mice are also reversed by EE. ${ }^{141,142}$ The fundamental mechanisms through which EE exerts its beneficial effects, that is, increased trophic factor expression, decreased inhibition and increased activity-dependent hystone acetylation, ${ }^{143}$ are all involved in the pathogenesis of ReS, thus indicating a strong rationale for the use of EE to treat ReS cognitive deficit.
Accordingly, BDNF is increased in the cerebellum of MeCP2 mutant mice exposed to $E E^{141}$ and systemic infusion of IGF-I partially reverts their ReS-like symptoms. ${ }^{144}$

Down's syndrome. Down's syndrome (DS) is caused by triplication of chromosome 21 (Chr21) and is the most diffused genetic cause of mental retardation. People with DS have marked cognitive deficits, with reduced IQ and learning and memory performances. ${ }^{145}$ During recent years, several murine models of DS have been generated, carrying triplications of different segments of Chr16, which has a high degree of synteny with human Chr21. ${ }^{146,147}$ The most intensively studied mouse model of DS is the Ts65Dn line, ${ }^{148}$ which summarizes the main hallmarks of the DS phenotype, including characteristic craniofacial abnormalities, impaired spatial and non-spatial learning abilities and attention deficits. ${ }^{149-154}$ At the cellular level, Ts65Dn mice have a reduced number of hippocampal and cerebellar neurons, ${ }^{155,156}$ impaired neurogenesis in the dentate gyrus of the hippocampus in both young and aged adults ${ }^{157,158}$ and a prominent reduction in dendritic branching in several brain regions, accompanied by alterations in spine size and shape. ${ }^{159}$ It is noteworthy that DS is also associated with reduced hippocampal neurogenesis ${ }^{160}$ and volume $^{161}$ in humans. Adult Ts65Dn mice show age-dependent degeneration of basal forebrain cholinergic neurons (BFCNs), ${ }^{162}$ the most characteristic neuropathological correlate of the late cognitive decline observed in Alzheimer's disease (AD). Virtually all persons born with $D S$ develop $A D$ if they live into their fourth decade of life. ${ }^{163,164}$ There is evidence that degeneration of BFCNs in Ts65Dn mice is related to a marked decrease in the NGF retrograde transport from the hippocampus to the basal forebrain. ${ }^{165,166}$ Intracerebroventricular NGF infusion reverses BFCN morphological abnormalities, restoring the deficit in cholinergic innervation. ${ }^{165}$ BDNF signalling in Ts65Dn mice is also disrupted. In the frontal cortex, lower levels of BDNF with respect to diploid animals are found and negatively correlated with the progressive deterioration of working memory performance. ${ }^{167}$

A major functional synaptic defect detectable in Ts65Dn mice is the failure to induce LTP in the hippocampus. ${ }^{168-171}$ This deficit has been attributed to excessive inhibition, ${ }^{171}$ a hypothesis recently confirmed by Fernandez et al., ${ }^{172}$ which showed that the spatial learning disabilities observed in Ts65Dn mice are rescued by administration of non-competitive antagonists of GABAA receptors. The impairment in synaptic plasticity is linked to marked morphological changes in the structure of synapses, with a selective enlargement of the active zones of asymmetric synapses and increased immunostaining for synaptic proteins marking inhibitory synapses. ${ }^{173}$

Given that $E E$ is particularly effective in reducing GABAergic inhibition and in enhancing neurotrophin expression, it has great potential for therapeutic application in the treatment of DS. Martinez-Cué et al. ${ }^{174,175}$ reported increased exploratory behaviour and enhanced spatial learning in EE Ts65Dn mice, although the effect was gender specific. At the cellular level, Ts65Dn mice raised in EE conditions have shown increased dendritic branching in the frontal cortex. ${ }^{176}$ Despite these 
results, a thorough analysis of the EE effects on mouse models of DS is still needed.

Alzheimer's disease. Alzheimer's disease is a neurodegenerative pathology leading to progressive memory loss and severe cognitive decline. The disease is characterized by two pathological hallmarks, mainly affecting the neocortex and hippocampus, that is, senile plaques (extracellular aggregates of $\beta$-amyloid derived from proteolysis of the precursor protein APP operated by the BACE enzyme) and neurofibrillary tangles (intraneuronal aggregations of hyperphosphorylated forms of the microtubule-associated protein tau). ${ }^{177,178}$ In addition, as mentioned before, AD is invariantly associated with marked degeneration of BFCNs. ${ }^{179}$ Most AD cases are sporadic and seem to result from an interaction of multiple genetic and still unknown environmental factors. However, there are also familial forms of $A D$ that are inherited in an autosomal dominant manner. Three genes have been involved in familial AD: APP, presenilin 1 (PS1) and presenilin 2 (PS2). The main mutations at the levels of these genes have all been targeted in transgenic mouse modelling studies. A genetic risk factor for the sporadic form of $A D$ has also been found in the $\varepsilon 4$ polymorphism of the apolipoprotein E (APOE) gene. ${ }^{180}$

Levi et al. ${ }^{181}$ were the first to examine the effect of differential rearing in a mouse model of $A D$, using transgenic mice expressing the human APOE3 or APOE4 alleles. Enriched mice transgenic for human APOE3 showed improved learning and memory associated with higher hippocampal levels of presynaptic protein synaptophysin and of NGF, whereas mice transgenic for human APOE4 were unaffected by EE. EE has repeatedly been reported to enhance performance in various cognitive tasks in transgenic mice carrying a double mutation at the level of both APP and PS1 genes, ${ }^{182,183}$ in mice carrying the so-called Swedish mutation (SweAPP), ${ }^{184-186}$ and in AD11 transgenic mice expressing a recombinant anti-NGF factor antibody. ${ }^{187}$

The effect of EE on $A \beta$ levels and plaque deposition, as well as their impact on cognitive improvement, is controversial. Jankowsky et al. ${ }^{182,188}$ unexpectedly reported that EE APP/ PS1 transgenic mice develop a higher amyloid burden with increases in aggregated and total $\mathrm{A} \beta$ levels, particularly in the hippocampus. Arendash et al. ${ }^{184}$ failed to observe any change in $\mathrm{A} \beta$ deposition in EE APP transgenic mice. In contrast, Lazarov et al. ${ }^{189}$ reported a decrease in hippocampal and cortical A $\beta$ levels and amyloid deposits in EE APP/PS1 transgenic animals compared with standard-housed controls. In addition, the enzymatic activity of neprilysin, an $\mathrm{A} \beta$-degrading endopeptidase, was found to be elevated in the brain of EE mice. ${ }^{189} \mathrm{~A}$ reduction in brain $\beta$-amyloid deposition after EE exposure has also been shown in APP, TgCRND8 and AD11 transgenic mice. ${ }^{186,187,190,191}$ Some studies have also investigated the effects of EE on neurogenesis in AD mouse models. Although conditional PS1 knockout mice and mice overexpressing either wild-type human PS1 or the mutant form P117L show a deficiency in EE-induced neurogenesis, ${ }^{192-194}$ it has been recently reported that $\mathrm{EE}$ promotes hippocampal neurogenesis in APP and TgCRND8 mice. ${ }^{185,191,195}$ Moreover, EE increases angiogenesis and facilitates blood $\mathrm{A} \beta$ clearance through a differential regulation of $\mathrm{A} \beta$ receptor/transporter molecules in TgCRND8 mice. ${ }^{196}$

Lazarov et al. ${ }^{189}$ carried out a microarray analysis to identify gene expression changes in APP/PS1 transgenic mice placed in EE conditions. This study revealed a total of 41 genes differentially regulated in response to EE, with the vast majority of genes that showed elevated expression encoding polypeptides involved in learning and memory, synaptic plasticity, neurogenesis, vasculogenesis, neuronal cell growth and cell survival pathways (e.g., NGF-1A, BDNF; CaMKIl $\alpha) .{ }^{189}$ It is particularly interesting that transthyretin, a protein involved in $\mathrm{A} \beta$ clearance, is upregulated in transgenic mice raised with EE. ${ }^{183}$ A quantitative RT-PCR study further confirmed that EE promotes the upregulation of trophic factor expression (NT-3, BDNF, IGF-I and VEGF) in the hippocampus of SweAPP mice. ${ }^{185}$ Finally, environmental stimulation attenuates pro-oxidative processes and triggers anti-oxidative defence mechanisms, as indicated by diminished biomarkers for reactive oxygen and nitrogen species, downregulation of proinflammatory and pro-oxidative mediators and upregulation of superoxide dismutase 1 (SOD1) and SOD2. ${ }^{197}$ Although the mechanisms underlying the beneficial effects of $E E$ on mouse models of $A D$ remain to be clarified in more detail, these studies indicate that an enhanced environmental stimulation may help in slowing down or preventing the cognitive decline associated with AD.

\section{Conclusions}

Altogether, the findings reviewed here show how dramatic the influence exerted by the environment can be on brain plasticity. Studies using the EE paradigm have indicated a number of molecular hotspots that might emerge as possible ways of accession for a successful treatment of neuropathological conditions affecting the juvenile and adult CNS. An open issue is the extent to which EE in animal models is relevant for the human living experience. EE is a complex paradigm, as an increased stimulation is provided at multiple sensory, motor, cognitive and social levels. Although most humans do experience a high degree of environmental complexity and novelty, levels of cognitive, social and physical stimulation vary greatly among individuals and in different periods of life. Strong correlative and epidemiological evidence shows that lifestyle, including occupation, leisure activities and physical exercise, has a direct effect on the risk of cognitive decline. Results indicate that a higher level and variety of mental and physical activity is associated with a lower cognitive decline and a reduced risk for dementia ${ }^{198-204}$. These results encourage stronger efforts in the application of $E E$ paradigms, alone or in combination with pharmacological treatments, for the therapy of neurological disorders.

\section{Conflict of interest}

The authors declare no conflict of interest.

1. Goodman CS, Shatz CJ. Developmental mechanisms that generate precise patterns of neuronal connectivity. Cell 1993; 72 (Suppl): 77-98

2. Katz LC, Shatz CJ. Synaptic activity and the construction of cortical circuits. Science 1996; 274: 1133-1138. 
3. Berardi N, Pizzorusso T, Maffei L. Critical periods during sesory development. Curr Opin Neurobiol 2000; 10: 138-145.

4. Hensch TK. Critical period regulation. Annu Rev Neurosci 2004; 27: 549-579.

5. Crowley JC, Katz LC. Ocular dominance development revisited. Curr Opin Neurobiol 2002; 12: 104-109.

6. Leamey CA, Van Wart A, Sur M. Intrinsic patterning and experience-dependent mechanisms that generate eye-specific projections and binocular circuits in the visual pathway. Curr Opin Neurobiol 2009; 19: 181-187.

7. Fregnac $Y$, Imbert M. Early development of visual cortical cells in normal and dark-reared kittens: relationship between orientation selectivity and ocular dominance. J Physiol 1978; 278: $27-44$.

8. Timney B, Mitchell DE, Giffin F. The development of vision in cats after extended periods of dark-rearing. Exp Brain Res 1978; 31: 547-560.

9. Benevento LA, Bakkum BW, Port JD, Cohen RS. The effects of dark-rearing on the electrophysiology of the rat visual cortex. Brain Res 1992; 572: 198-207.

10. Fagiolini M, Pizzorusso T, Berardi N, Domenici L, Maffei L. Functional postnatal development of the rat primary visual cortex and the role of visual experience: dark rearing and monocular deprivation. Vision Res 1994; 34: 709-720.

11. Wiesel TN, Hubel DH. Single-Cell Responses in Striate Cortex of Kittens Deprived of Vision in One Eye. J Neurophysiol 1963; 26: 1003-1017.

12. Hubel $\mathrm{DH}$, Wiesel TN. The period of susceptibility to the physiological effects of unilateral eye closure in kittens. J Physiol 1970; 206: 419-436.

13. Hubel $\mathrm{DH}$, Wiesel TN, LeVay S. Plasticity of ocular dominance columns in monkey striate cortex. Philos Trans R Soc Lond B Biol Sci 1977; 278: 377-409.

14. Van Sluyters RC, Stewart DL. Binocular neurons of the rabbit's visual cortex: effects of monocular sensory deprivation. Exp Brain Res 1974; 19: 196-204.

15. Emerson VF, Chalupa LM, Thompson ID, Talbot RJ. Behavioural, physiological, and anatomical consequences of monocular deprivation in the golden hamster (Mesocricetus auratus). Exp Brain Res 1982; 45: 168-178.

16. Gordon JA, Stryker MP. Experience-dependent plasticity of binocular responses in the primary visual cortex of the mouse. J Neurosci 1996; 16: 3274-3286.

17. Issa NP, Trachtenberg JT, Chapman B, Zahs KR, Stryker MP. The critical period for ocular dominance plasticity in the Ferret's visual cortex. J Neurosci 1999; 19: 6965-6978.

18. Rosenzweig MR, Bennett EL, Hebert M, Morimoto H. Social grouping cannot account for cerebral effects of enriched environments. Brain Res 1978; 153: 563-576.

19. Rampon C, Tsien JZ. Genetic analysis of learning behavior-induced structural plasticity. Hippocampus 2000; 10: 605-609.

20. Chapillon P, Patin V, Roy V, Vincent A, Caston J. Effects of pre- and postnatal stimulation on developmental, emotional, and cognitive aspects in rodents: a review. Dev Psychobio 2002; 41: 373-387.

21. van Praag H, Kempermann G, Gage FH. Neural consequences of environmental enrichment. Nat Rev Neurosci 2000; 1: 191-198.

22. Mohammed AH, Zhu SW, Darmopil S, Hjerling-Leffler J, Ernfors P, Winblad B et al. Environmental enrichment and the brain. Prog Brain Res 2002; 138: 109-133.

23. Rampon $\mathrm{C}$, Jiang $\mathrm{CH}$, Dong $\mathrm{H}$, Tang YP, Lockhart DJ, Schultz PG et al. Effects of environmental enrichment on gene expression in the brain. Proc Natl Acad Sci USA 2000 97: $12880-12884$

24. Rosenzweig MR, Bennett EL, Diamond MC. Effects of differential environments on brain anatomy and brain chemistry. Proc Annu Meet Am Psychopathol Assoc 1967; 56: $45-56$.

25. Rasmuson S, Olsson T, Henriksson BG, Kelly PA, Holmes MC, Seckl JR et al. Environmental enrichment selectively increases $5-\mathrm{HT} 1 \mathrm{~A}$ receptor mRNA expression and binding in the rat hippocampus. Brain Res Mol Brain Res 1998; 53: 285-290.

26. Ickes BR, Pham TM, Sanders LA, Albeck DS, Mohammed AH, Granholm AC. Long-term environmental enrichment leads to regional increases in neurotrophin levels in rat brain Exp Neurol 2000; 164: 45-52

27. Naka F, Shiga T, Yaguchi M, Okado N. An enriched environment increases noradrenaline concentration in the mouse brain. Brain Res 2002; 924: 124-126.

28. Rosenzweig MR, Bennett EL. Effects of differential environments on brain weights and enzyme activities in gerbils, rats, and mice. Dev Psychobiol 1969; 2: 87-95.

29. Cornwell $P$, Overman W. Behavioral effects of early rearing conditions and neonatal lesions of the visual cortex in kittens. J Comp Physiol Psychol 1981; 95: 848-862.

30. Hansen LT, Berthelsen $\mathrm{H}$. The effect of environmental enrichment on the behaviour of caged rabbits (Oryctolagus cuniculus). Appl Anim Behav Sci 2000; 68: 163-178.

31. Kozorovitskiy Y, Gross CG, Kopil C, Battaglia L, McBreen M, Stranahan AM et al. Experience induces structural and biochemical changes in the adult primate brain. Proc Natl Acad Sci USA 2005; 102: 17478-17482.

32. Jansen J, Bolhuis JE, Schouten WG, Spruijt BM, Wiegant VM. Spatial learning in pigs: effects of environmental enrichment and individual characteristics on behaviour and performance. Anim Cogn 2009; 12: 303-315.

33. Prusky GT, Reidel C, Douglas RM. Environmental enrichment from birth enhances visual acuity but not place learning in mice. Behav Brain Res 2000; 114: 11-15.

34. Cancedda L, Putignano E, Sale A, Viegi A, Berardi N, Maffei L. Acceleration of visual system development by environmental enrichment. J Neurosci 2004; 24: 4840-4848.

35. Sale A, Putignano E, Cancedda L, Landi S, Cirulli F, Berardi N et al. Enriched environment and acceleration of visual system development. Neuropharmacology 2004; 47: 649-660.
36. Landi S, Cenni MC, Maffei L, Berardi N. Environmental enrichment effects on development of retinal ganglion cell dendritic stratification require retinal BDNF. PLOS One 2007; 2: e346.

37. Kirkwood A, Lee HK, Bear MF. Co-regulation of long-term potentiation and experiencedependent synaptic plasticity in visual cortex by age and experience. Nature 1995; 375 : 328-331.

38. Bartoletti A, Medini P, Berardi N, Maffei L. Environmental enrichment prevents effects of dark-rearing in the rat visual cortex. Nat Neurosci 2004; 7: 215-216.

39. Cai R, Guo F, Zhang J, Xu J, Cui Y, Sun X. Environmental enrichment improves behavioral performance and auditory spatial representation of primary auditory cortical neurons in rat. Neurobiol Learn Mem 2009; 91: 366-376.

40. Huang ZJ, Kirkwood A, Pizzorusso T, Porciatti V, Morales B, Bear MF et al. BDNF regulates the maturation of inhibition and the critical period of plasticity in mouse visual cortex. Cell 1999; 98: 739-755.

41. Gianfranceschi L, Siciliano R, Walls J, Morales B, Kirkwood A, Huang ZJ et al. Visual cortex is rescued from the effects of dark rearing by overexpression of BDNF. Proc Natl Acad Sci USA 2003; 100: 12486-12491.

42. Ciucci F, Putignano E, Baroncelli L, Landi S, Berardi N, Maffei L. Insulin-like growth factor 1 (IGF-1) mediates the effects of enriched environment (EE) on visual cortical development. PLoS One 2007; 2: e475.

43. Tian N, Copenhagen DR. Visual deprivation alters development of synaptic function in inner retina after eye opening. Neuron 2001; 32: 439-449.

44. Tian N, Copenhagen DR. Visual stimulation is required for refinement of ON and OFF pathways in postnatal retina. Neuron 2003; 39: 85-96.

45. Landi S, Sale A, Berardi N, Viegi A, Maffei L, Cenni MC. Retinal functional development is sensitive to environmental enrichment: a role for BDNF. FASEB J 2007; 21: 130-139.

46. Landi S, Ciucci F, Maffei L, Berardi N, Cenni MC. Setting the pace for retinal development: environmental enrichment acts through insulin-like growth factor 1 and brain-derived neurotrophic factor. J Neurosci 2009; 29: 10809-10819.

47. Sale A, Cenni MC, Ciucci F, Putignano E, Chierzi S, Maffei L. Maternal enrichment during pregnancy accelerates retinal development of the fetus. PLOS One 2007; 2: e1160.

48. Bick-Sander A, Steiner B, Wolf SA, Babu H, Kempermann G. Running in pregnancy transiently increases postnatal hippocampal neurogenesis in the offspring. Proc Natl Acad Sci USA 2006; 103: 3852-3857.

49. Lee HH, Kim H, Lee JW, Kim YS, Yang HY, Chang HK et al. Maternal swimming during pregnancy enhances short-term memory and neurogenesis in the hippocampus of rat pups. Brain Dev 2006; 28: 147-154.

50. Liu D, Diorio J, Day JC, Francis DD, Meaney MJ. Maternal care, hippocampa synaptogenesis and cognitive development in rats. Nat Neurosci 2000; 3: 799-806.

51. Weaver IC, Cervoni N, Champagne FA, D'Alessio AC, Sharma S, Seckl JR et al. Epigenetic programming by maternal behavior. Nat Neurosci 2004; 7: 847-854.

52. Weaver IC, Meaney MJ, Szyf M. Maternal care effects on the hippocampal transcriptome and anxiety-mediated behaviors in the offspring that are reversible in adulthood. Proc Natl Acad Sci USA 2006; 103: 3480-3485

53. Champagne FA, Curley JP. Epigenetic mechanisms mediating the long-term effects of maternal care on development. Neurosci Biobehav Rev 2009; 33: 593-600.

54. Guzzetta A, Baldini S, Bancale A, Baroncelli L, Ciucci F, Ghirri P et al. Massage accelerates brain development and the maturation of visual function. J Neurosci 2009; 29 : 6042-6051

55. Schanberg SM, Field TM. Sensory deprivation stress and supplemental stimulation in the rat pup and preterm human neonate. Child Dev 1987; 58: 1431-1447.

56. Chatterjee D, Chatterjee-Chakraborty M, Rees S, Cauchi J, de Medeiros CB, Fleming AS Maternal isolation alters the expression of neural proteins during development: 'Stroking' stimulation reverses these effects. Brain Res 2007; 1158: 11-27.

57. Burton CL, Chatterjee D, Chatterjee-Chakraborty M, Lovic V, Grella SL, Steiner M et al. Prenatal restraint stress and motherless rearing disrupts expression of plasticity markers and stress-induced corticosterone release in adult female Sprague-Dawley rats. Brain Res 2007; 1158: 28-38.

58. Field T, Diego M, Hernandez-Reif M, Dieter JN, Kumar AM, Schanberg S et al. Insulin and insulin-like growth factor-1 increased in preterm neonates following massage therapy. J Dev Behav Pediatr 2008; 29: 463-466.

59. Lofquist C, Andersson E, Sigurdsson J, Engstrom E, Hard AL, Niklasson A et al. Longitudinal postnatal weight and insulin-like growth factor I measurements in the prediction of retinopathy of prematurity. Arch Ophthalmol 2006; 124: 1711-1718.

60. Lofqvist C, Chen J, Connor KM, Smith AC, Aderman CM, Liu N et al. IGFBP3 suppresses retinopathy through suppression of oxygen-induced vessel loss and promotion of vascular regrowth. Proc Natl Acad Sci USA 2007; 104: 10589-10594.

61. Holmes JM, Clarke MP. Amblyopia. Lancet 2006; 367: 1343-1351.

62. Lewis TL, Maurer D. Multiple sensitive periods in human visual development: evidence from visually deprived children. Dev Psychobiol 2005; 46: 163-183.

63. Levi DM. Visual processing in amblyopia: human studies. Strabismus 2006; 14 $11-19$.

64. Timney B. The effects of early and late monocular deprivation on binocular depth perception in cats. Brain Res 1983; 283: 235-243.

65. Kiorpes L, Kiper DC, O'Keefe LP, Cavanaugh JR, Movshon JA. Neuronal correlates of amblyopia in the visual cortex of macaque monkeys with experimental strabismus and anisometropia. J Neurosci 1998; 18: 6411-6424. 
66. Maurer D, Lewis TL, Brent HP, Levin AV. Rapid improvement in the acuity of infants afte visual input. Science 1999; 286: 108-110.

67. Prusky GT, West PW, Douglas RM. Experience-dependent plasticity of visual acuity in rats. Eur J Neurosci 2000; 12: 3781-3786.

68. Prusky GT, Douglas RM. Developmental plasticity of mouse visual acuity. Eur J Neurosci 2003; 17: 167-173.

69. Wu C, Hunter DG. Amblyopia: diagnostic and therapeutic options. Am J Ophthalmol 2006; 141: 175-184.

70. Spolidoro M, Sale A, Berardi N, Maffei L. Plasticity in the adult brain: lessons from the visual system. Exp Brain Res 2009; 192: 335-341.

71. Sale A, Maya Vetencourt JF, Medini P, Cenni MC, Baroncelli L, De Pasquale R et al. Environmental enrichment in adulthood promotes amblyopia recovery through a reduction of intracortical inhibition. Nat Neurosci 2007; 10: 679-681.

72. Fagiolini M, Hensch TK. Inhibitory threshold for critical-period activation in primary visual cortex. Nature 2000; 404: 183-186.

73. Maya Vetencourt JF, Sale A, Viegi A, Baroncelli L, De Pasquale R, O'Leary OF et al. The antidepressant fluoxetine restores plasticity in the adult visual cortex. Science 2008; 320 : 385-388.

74. He HY, Hodos W, Quinlan EM. Visual deprivation reactivates rapid ocular dominance plasticity in adult visual cortex. J Neurosci 2006; 26: 2951-2955.

75. He HY, Ray B, Dennis K, Quinlan EM. Experience-dependent recovery of vision following chronic deprivation amblyopia. Nat Neurosci 2007; 10: 1134-1136.

76. Levi DM, Polat U. Neural plasticity in adults with amblyopia. Proc Natl Acad Sci USA 1996; 93: 6830-6834

77. Levi DM, Polat U, Hu YS. Improvement in Vernier acuity in adults with amblyopia. Practice makes better. Invest Ophthalmol Vis Sci 1997; 38: 1493-1510.

78. Polat U, Ma-Naim T, Belkin M, Sagi D. Improving vision in adult amblyopia by perceptua learning. Proc Natl Acad Sci USA 2004; 101: 6692-6697.

79. Levi DM. Perceptual learning in adults with amblyopia: a reevaluation of critical periods in human vision. Dev Psychobiol 2005; 46: 222-232.

80. Polat U. Restoration of underdeveloped cortical functions: evidence from treatment of adult amblyopia. Restor Neurol Neurosci 2008; 26: 413-424

81. Levi DM, Li RW. Improving the performance of the amblyopic visual system. Philos Trans $R$ Soc Lond B Biol Sci 2009; 364: 399-407.

82. Fahle M. Perceptual learning: specificity versus generalization. Curr Opin Neurobiol 2005 15: $154-160$.

83. Polat U, Sagi D, Norcia AM. Abnormal long-range spatial interactions in amblyopia. Vision Res 1997; 37: 737-744.

84. Polat U. Functional architecture of long-range perceptual interactions. Spat Vis 1999; 12: 143-162.

85. Levi DM, Hariharan S, Klein SA. Suppressive and facilitatory spatial interactions in amblyopic vision. Vision Res 2002; 42: 1379-1394.

86. Polat U, Bonneh Y, Ma-Naim T, Belkin M, Sagi D. Spatial interactions in amblyopia: effects of stimulus parameters and amblyopia type. Vision Res 2005; 45: 1471-1479.

87. Wong EH, Levi DM, McGraw PV. Spatial interactions reveal inhibitory cortical networks in human amblyopia. Vision Res 2005; 45: 2810-2819.

88. Kaneko M, Hanover JL, England PM, Stryker MP. TrkB kinase is required for recovery, but not loss, of cortical responses following monocular deprivation. Nat Neurosci 2008 ; 11: 497-504.

89. Fischer A, Sananbenesi F, Wang X, Dobbin M, Tsai LH. Recovery of learning and memory is associated with chromatin remodelling. Nature 2007; 447: 178-182.

90. Putignano E, Lonetti G, Cancedda L, Ratto G, Costa M, Maffei L et al. Developmental downregulation of histone posttranslational modifications regulates visual cortical plasticity. Neuron 2007; 53: 747-759.

91. Finkbeiner S, Tavazoie SF, Maloratsky A, Jacobs KM, Harris KM, Greenberg ME. CREB: a major mediator of neuronal neurotrophin responses. Neuron 1997; 19: 1031-1047.

92. Pizzorusso T, Ratto GM, Putignano E, Maffei L. Brain-derived neurotrophic factor causes CAMP response element-binding protein phosphorylation in absence of calcium increases in slices and cultured neurons from rat visual cortex. $J$ Neurosci 2000; 20: 2809-2816.

93. Ratto GM, Pizzorusso T. A kinase with a vision: Role of ERK in the synaptic plasticity of the visual cortex. Adv Exp Med Biol 2006; 557: 122-132.

94. Pham TA, Impey S, Storm DR, Stryker MP. CRE-mediated gene transcription in neocortical neuronal plasticity during the developmental critical period. Neuron 1999; 22: 63-72.

95. Mower AF, Liao DS, Nestler EJ, Neve RL, Ramoa AS. cAMP/Ca2+ response elementbinding protein function is essential for ocular dominance plasticity. J Neurosci 2002; 22 2237-2245.

96. Pham TA, Graham SJ, Suzuki S, Barco A, Kandel ER, Gordon B et al. A semi-persisten adult ocular dominance plasticity in visual cortex is stabilized by activated CREB. Learn Mem 2004; 11: 738-747.

97. Lonze BE, Ginty DD. Function and regulation of CREB family transcription factors in the nervous system. Neuron 2002; 35: 605-623.

98. Williams BM, Luo Y, Ward C, Redd K, Gibson R, Kuczaj SA et al. Environmental enrichment: effects on spatial memory and hippocampal CREB immunoreactivity. Physio Behav 2001; 73: 649-658.

99. Pizzorusso T, Medini P, Berardi N, Chierzi S, Fawcett JW, Maffei L. Reactivation of ocula dominance plasticity in the adult visual cortex. Science 2002: 298: 1248-1251.
100. Pizzorusso T, Medini P, Landi S, Baldini S, Berardi N, Maffei L. Structural and functional recovery from early monocular deprivation in adult rats. Proc Natl Acad Sci USA 2006; 103: 8517-8522.

101. Gu Q. Neuromodulatory transmitter systems in the cortex and their role in cortical plasticity. Neuroscience 2002; 111: 815-835

102. Rosenzweig MR, Krech D, Bennett EL, Diamond MC. Effects of environmental complexity and training on brain chemistry and anatomy: a replication and extension. J Comp Physiol Psychol 1962; 55: 429-437.

103. Escorihuela RM, Fernandez-Teruel A, Tobena A, Vivas NM, Marmol F, Badia A et al. Early environmental stimulation produces long-lasting changes on beta-adrenoceptor transduction system. Neurobiol Learn Mem 1995; 64: 49-57.

104. Galani R, Berthel MC, Lazarus C, Majchrzak M, Barbelivien A, Kelche C et al. The behavioral effects of enriched housing are not altered by serotonin depletion but enrichment alters hippocampal neurochemistry. Neurobiol Learn Mem 2007; 88: 1-10.

105. Brenes JC, Rodriguez O, Fornaguera J. Differential effect of environment enrichment and social isolation on depressive-like behavior, spontaneous activity and serotonin and norepinephrine concentration in prefrontal cortex and ventral striatum. Pharmacol Biochem Behav 2008; 89: 85-93.

106. Madison DV, Nicoll RA. Norepinephrine decreases synaptic inhibition in the rat hippocampus. Brain Res 1988; 442: 131-138.

107. Schmitz D, Empson RM, Heinemann U. Serotonin reduces inhibition via 5-HT1A receptors in area CA1 of rat hippocampal slices in vitro. J Neurosci 1995; 15: 7217-7225.

108. Kawaguchi $Y$, Shindou T. Noradrenergic excitation and inhibition of GABAergic cell types in rat frontal cortex. J Neurosci 1998; 18: 6963-6976.

109. Xiang Z, Huguenard JR, Prince DA. Cholinergic switching within neocortical inhibitory networks. Science 1998; 281: 985-988.

110. Martin LA, Alger BE. Muscarinic facilitation of the occurrence of depolarization-induced suppression of inhibition in rat hippocampus. Neuroscience 1999; 92: 61-71.

111. Zhou FM, Hablitz JJ. Activation of serotonin receptors modulates synaptic transmission in rat cerebral cortex. J Neurophysiol 1999; 82: 2989-2999.

112. Gao WJ, Wang Y, Goldman-Rakic PS. Dopamine modulation of perisomatic and peridendritic inhibition in prefrontal cortex. J Neurosci 2003; 23: 1622-1630.

113. Xiang Z, Prince DA. Heterogeneous actions of serotonin on interneurons in rat visual cortex. J Neurophysiol 2003; 89: 1278-1287.

114. Kurotani T, Yamada K, Yoshimura Y, Crair MC, Komatsu Y. State-dependent bidirectional modification of somatic inhibition in neocortical pyramidal cells. Neuron 2008; 57: 905-916.

115. Nibuya M, Morinobu S, Duman RS. Regulation of BDNF and trkB mRNA in rat brain by chronic electroconvulsive seizure and antidepressant drug treatments. J Neurosci 1995; 15: $7539-7547$.

116. Vaidya VA, Marek GJ, Aghajanian GK, Duman RS. 5-HT2A receptor-mediated regulation of brain-derived neurotrophic factor mRNA in the hippocampus and the neocortex. J Neurosci 1997; 17: 2785-2795.

117. Zetterstrom TS, Pei Q, Madhav TR, Coppell AL, Lewis L, Grahame-Smith DG. Manipulations of brain 5-HT levels affect gene expression for BDNF in rat brain. Neuropharmacology 1999; 38: 1063-1073.

118. Castren E. Neurotrophic effects of antidepressant drugs. Curr Opin Pharmacol 2004; 4: 58-64

119. Robbins TW. Arousal systems and attentional processes. Biol Psychol 1997; 45: 57-71.

120. Coull JT. Neural correlates of attention and arousal: insights from electrophysiology, functional neuroimaging and psychopharmacology. Prog Neurobiol 1998; 55: 343-361.

121. Boulougouris V, Tsaltas E. Serotonergic and dopaminergic modulation of attentional processes. Prog Brain Res 2008; 172: 517-542.

122. Li R, Polat U, Makous W, Bavelier D. Enhancing the contrast sensitivity function through action video game training. Nat Neurosci 2009; 12: 549-551.

123. Green CS, Bavelier D. Action video game modifies visual selective attention. Nature 2003; 423: 534-537.

124. Caplovitz GP, Kastner S. Carrot sticks or joysticks: video games improve vision. Nat Neurosci 2009; 12: 527-528.

125. Will B, Galani R, Kelche C, Rosenzweig MR. Recovery from brain injury in animals: relative efficacy of environmental enrichment, physical exercise or formal training (1990-2002). Prog Neurobiol 2004; 72: 167-182.

126. Nithianantharajah J, Hannan AJ. Enriched environments, experience-dependent plasticity and disorders of the nervous system. Nat Rev Neurosci 2006; 7: 697-709.

127. Hagberg B, Aicardi J, Dias K, Ramos O. A progressive syndrome of autism, dementia, ataxia, and loss of purposeful hand use in girls: Rett's syndrome: report of 35 cases. Ann Neurol 1983; 14: 471-479.

128. Amir RE, Van den Veyver IB, Wan M, Tran CQ, Francke $U$, Zoghbi HY. Rett syndrome is caused by mutations in X-linked MECP2, encoding methyl-CpG-binding protein 2. Nat Genet 1999; 23: 185-188.

129. Chahrour M, Jung SY, Shaw C, Zhou X, Wong ST, Qin J et al. MeCP2, a key contributor to neurological disease, activates and represses transcription. Science 2008; 320: 1224-1229.

130. Young Jl, Hong EP, Castle JC, Crespo-Barreto J, Bowman AB, Rose MF et al. Regulation of RNA splicing by the methylation-dependent transcriptional repressor methyl-CpG binding protein 2. Proc Natl Acad Sci USA 2005; 102: 17551-17558.

131. Guy J, Hendrich B, Holmes M, Martin JE, Bird A. A mouse Mecp2-null mutation causes neurological symptoms that mimic Rett syndrome. Nat Genet 2001; 27: 322-326. 
132. Chen RZ, Akbarian S, Tudor M, Jaenisch R. Deficiency of methyl-CpG binding protein-2 in CNS neurons results in a Rett-like phenotype in mice. Nat Genet 2001; 27: 327-331.

133. Moretti P, Bouwknecht JA, Teague R, Paylor R, Zoghbi HY. Abnormalities of social interactions and home-cage behavior in a mouse model of Rett syndrome. Hum $\mathrm{Mol}$ Genet 2005; 14: 205-220.

134. Stearns NA, Schaevitz LR, Bowling H, Nag N, Berger UV, Berger-Sweeney J. Behavioral and anatomical abnormalities in Mecp2 mutant mice: a model for Rett syndrome. Neuroscience 2007; 146: 907-921

135. Dani VS, Chang Q, Maffei A, Turrigiano GG, Jaenisch R, Nelson SB. Reduced cortical activity due to a shift in the balance between excitation and inhibition in a mouse model of Rett syndrome. Proc Natl Acad Sci USA 2005; 102: 12560-12565.

136. Asaka Y, Jugloff DG, Zhang L, Eubanks JH, Fitzsimonds RM. Hippocampal synaptic plasticity is impaired in the Mecp2-null mouse model of Rett syndrome. Neurobiol Dis 2006; 21: 217-227.

137. Fernandez F, Garner CC. Over-inhibition: a model for developmental intellectual disability. Trends Neurosci 2007; 30: 497-503.

138. Moretti $P$, Levenson JM, Battaglia F, Atkinson R, Teague R, Antalffy $B$ et al. Learning and memory and synaptic plasticity are impaired in a mouse model of Rett syndrome. $J$ Neurosci 2006; 26: 319-327.

139. Chen WG, Chang Q, Lin Y, Meissner A, West AE, Griffith EC et al. Derepression of BDNF transcription involves calcium-dependent phosphorylation of MeCP2. Science 2003; 302: 885-889.

140. Chang Q, Khare G, Dani V, Nelson S, Jaenisch R. The disease progression of Mecp2 mutant mice is affected by the level of BDNF expression. Neuron 2006; 49 341-348.

141. Kondo M, Gray LJ, Pelka GJ, Christodoulou J, Tam PP, Hannan AJ. Environmental enrichment ameliorates a motor coordination deficit in a mouse model of Rett syndromeMecp2 gene dosage effects and BDNF expression. Eur J Neurosci 2008; 27: 3342-3350.

142. Nag N, Moriuchi JM, Peitzman CG, Ward BC, Kolodny NH, Berger-Sweeney JE. Environmental enrichment alters locomotor behaviour and ventricular volume in Mecp2 1lox mice. Behav Brain Res 2009; 196: 44-48.

143. Sale A, Berardi N, Maffei $L$. Enrich the environment to empower the brain. Trends Neurosci 2009; 32: 233-239.

144. Tropea D, Giacometti E, Wilson NR, Beard C, McCurry C, Fu DD et al. Partial reversal of Rett syndrome-like symptoms in MeCP2 mutant mice. Proc Natl Acad Sci USA 2009; 106 2029-2034.

145. Pennington BF, Moon J, Edgin J, Stedron J, Nadel L. The neuropsychology of Down syndrome: evidence for hippocampal dysfunction. Child Dev 2003; 74: 75-93.

146. Antonarakis SE, Epstein CJ. The challenge of Down syndrome. Trends Mol Med 2006; 12: $473-479$

147. Seregaza Z, Roubertoux PL, Jamon M, Soumireu-Mourat B. Mouse models of cognitive disorders in trisomy 21: a review. Behav Genet 2006; 36: 387-404.

148. Gardiner K, Fortna A, Bechtel L, Davisson MT. Mouse models of Down syndrome: how useful can they be? Comparison of the gene content of human chromosome 21 with orthologous mouse genomic regions. Gene 2003; 318: 137-147.

149. Richtsmeier JT, Zumwalt A, Carlson EJ, Epstein CJ, Reeves RH. Craniofacial phenotypes in segmentally trisomic mouse models for Down syndrome. Am J Med Genet 2002; 107: 317-324.

150. Hunter CL, Bimonte HA, Granholm AC. Behavioral comparison of 4 and 6 month-old Ts65Dn mice: age-related impairments in working and reference memory. Behav Brain Res 2003; 138: 121-131.

151. Driscoll LL, Carroll JC, Moon J, Crnic LS, Levitsky DA, Strupp BJ. Impaired sustained attention and error-induced stereotypy in the aged Ts65Dn mouse: a mouse model of Down syndrome and Alzheimer's disease. Behav Neurosci 2004; 118: 1196-1205.

152. Stasko MR, Costa AC. Experimental parameters affecting the Morris water maze performance of a mouse model of Down syndrome. Behav Brain Res 2004; 154: 1-17.

153. Wenger GR, Schmidt C, Davisson MT. Operant conditioning in the Ts65Dn mouse: learning. Behav Genet 2004; 34: 105-119.

154. Costa AC, Scott-McKean JJ, Stasko MR. Acute injections of the NMDA receptor antagonist memantine rescue performance deficits of the Ts65Dn mouse model of Down syndrome on a fear conditioning test. Neuropsychopharmacology 2008; 33 : 1624-1632.

155. Insausti AM, Megias M, Crespo D, Cruz-Orive LM, Dierssen M, Vallina IF et al. Hippocampal volume and neuronal number in Ts65Dn mice: a murine model of Down syndrome. Neurosci Lett 1998; 253: 175-178.

156. Roper RJ, Baxter LL, Saran NG, Klinedinst DK, Beachy PA, Reeves RH. Defective cerebellar response to mitogenic Hedgehog signaling in Down [corrected] syndrome mice. Proc Natl Acad Sci USA 2006; 103: 1452-1456.

157. Rueda N, Mostany R, Pazos A, Florez J, Martinez-Cue C. Cell proliferation is reduced in the dentate gyrus of aged but not young Ts65Dn mice, a model of Down syndrome. Neurosci Lett 2005; 380: 197-201

158. Clark S, Schwalbe J, Stasko MR, Yarowsky PJ, Costa AC. Fluoxetine rescues deficient neurogenesis in hippocampus of the Ts65Dn mouse model for Down syndrome. Exp Neurol 2006; 200: 256-261.

159. Belichenko PV, Masliah E, Kleschevnikov AM, Villar AJ, Epstein CJ, Salehi A et al. Synaptic structural abnormalities in the Ts65Dn mouse model of Down syndrome. J Comp Neurol 2004; 480: 281-298.
160. Guidi S, Bonasoni P, Ceccarelli C, Santini D, Gualtieri F, Ciani E et al. Neurogenesis impairment and increased cell death reduce total neuron number in the hippocampal region of fetuses with Down syndrome. Brain Pathol 2008; 18: 180-197.

161. Aylward EH, Li Q, Honeycutt NA, Warren AC, Pulsifer MB, Barta PE et al. MRI volumes of the hippocampus and amygdala in adults with Down's syndrome with and without dementia. Am J Psychiatry 1999; 156: 564-568.

162. Granholm AC, Sanders LA, Crnic LS. Loss of cholinergic phenotype in basal forebrain coincides with cognitive decline in a mouse model of Down's syndrome. Exp Neurol 2000 161: $647-663$.

163. Isacson O, Seo H, Lin L, Albeck D, Granholm AC. Alzheimer's disease and Down's syndrome: roles of APP, trophic factors and ACh. Trends Neurosci 2002; 25: 79-84.

164. Lott IT, Head E. Alzheimer disease and Down syndrome: factors in pathogenesis. Neurobiol Aging 2005; 26: 383-389.

165. Cooper JD, Salehi A, Delcroix JD, Howe CL, Belichenko PV, Chua-Couzens J et al. Failed retrograde transport of NGF in a mouse model of Down's syndrome: reversal of cholinergic neurodegenerative phenotypes following NGF infusion. Proc Natl Acad Sci USA 2001; 98: 10439-10444.

166. Salehi A, Delcroix JD, Belichenko PV, Zhan K, Wu C, Valletta JS et al. Increased App expression in a mouse model of Down's syndrome disrupts NGF transport and causes cholinergic neuron degeneration. Neuron 2006; 51: 29-42.

167. Bimonte-Nelson HA, Hunter CL, Nelson ME, Granholm AC. Frontal cortex BDNF levels correlate with working memory in an animal model of Down syndrome. Behav Brain Res 2003; 139: 47-57.

168. Siarey RJ, Stoll J, Rapoport SI, Galdzicki Z. Altered long-term potentiation in the young and old Ts65Dn mouse, a model for Down syndrome. Neuropharmacology 1997; 36: 1549-1554.

169. Siarey RJ, Carlson EJ, Epstein CJ, Balbo A, Rapoport SI, Galdzicki Z. Increased synaptic depression in the Ts65Dn mouse, a model for mental retardation in Down syndrome. Neuropharmacology 1999; 38: 1917-1920.

170. Galdzicki Z, Siarey R, Pearce R, Stoll J, Rapoport SI. On the cause of mental retardation in Down syndrome: extrapolation from full and segmental trisomy 16 mouse models. Brain Res Brain Res Rev 2001; 35: 115-145.

171. Kleschevnikov AM, Belichenko PV, Villar AJ, Epstein CJ, Malenka RC, Mobley WC Hippocampal long-term potentiation suppressed by increased inhibition in the Ts65Dn mouse, a genetic model of Down syndrome. J Neurosci 2004; 24: 8153-8160.

172. Fernandez F, Morishita W, Zuniga E, Nguyen J, Blank M, Malenka RC et al. Pharmacotherapy for cognitive impairment in a mouse model of Down syndrome. Nat Neurosci 2007; 10: 411-413.

173. Belichenko PV, Kleschevnikov AM, Masliah E, Wu C, Takimoto-Kimura R, Salehi A et al. Excitatory-inhibitory relationship in the fascia dentata in the Ts65Dn mouse model of Down syndrome. J Comp Neurol 2009; 512: 453-466.

174. Martinez-Cue C, Baamonde C, Lumbreras M, Paz J, Davisson MT, Schmidt C et al. Differential effects of environmental enrichment on behavior and learning of male and female Ts65Dn mice, a model for Down syndrome. Behav Brain Res 2002; 134: 185-200.

175. Martinez-Cue C, Rueda N, Garcia E, Davisson MT, Schmidt C, Florez J. Behavioral, cognitive and biochemical responses to different environmental conditions in male Ts65Dn mice, a model of Down syndrome. Behav Brain Res 2005; 163: 174-185

176. Dierssen M, Benavides-Piccione R, Martinez-Cue C, Estivill X, Florez J, Elston GN et al. Alterations of neocortical pyramidal cell phenotype in the Ts65Dn mouse model of Down syndrome: effects of environmental enrichment. Cereb Cortex 2003; 13: 758-764.

177. Selkoe DJ. Altered structural proteins in plaques and tangles: what do they tell us about the biology of Alzheimer's disease? Neurobiol Aging 1986; 7: 425-432.

178. Goedert M, Sisodia SS, Price DL. Neurofibrillary tangles and beta-amyloid deposits in Alzheimer's disease. Curr Opin Neurobiol 1991; 1: 441-447.

179. Coyle JT, Price DL, DeLong MR. Alzheimer's disease: a disorder of cortical cholinergic innervation. Science 1983; 219: 1184-1190.

180. Price DL, Sisodia SS. Mutant genes in familial Alzheimer's disease and transgenic models. Annu Rev Neurosci 1998; 21: 479-505

181. Levi O, Jongen-Relo AL, Feldon J, Roses AD, Michaelson DM. ApoE4 impairs hippocampal plasticity isoform-specifically and blocks the environmental stimulation of synaptogenesis and memory. Neurobiol Dis 2003; 13: 273-282.

182. Jankowsky JL, Melnikova T, Fadale DJ, Xu GM, Slunt HH, Gonzales V et al. Environmental enrichment mitigates cognitive deficits in a mouse model of Alzheimer's disease. J Neurosci 2005; 25: 5217-5224.

183. Costa DA, Cracchiolo JR, Bachstetter AD, Hughes TF, Bales KR, Paul SM et al. Enrichment improves cognition in $A D$ mice by amyloid-related and unrelated mechanisms. Neurobiol Aging 2007; 28: 831-844.

184. Arendash GW, Garcia MF, Costa DA, Cracchiolo JR, Wefes IM, Potter H. Environmental enrichment improves cognition in aged Alzheimer's transgenic mice despite stable betaamyloid deposition. Neuroreport 2004; 15: 1751-1754.

185. Wolf SA, Kronenberg G, Lehmann K, Blankenship A, Overall R, Staufenbiel M et al. Cognitive and physical activity differently modulate disease progression in the amyloid precursor protein (APP)-23 model of Alzheimer's disease. Biol Psychiatry 2006; 60: 1314-1323.

186. Cracchiolo JR, Mori T, Nazian SJ, Tan J, Potter H, Arendash GW. Enhanced cognitive activity - over and above social or physical activity - is required to protect Alzheimer's mice against cognitive impairment, reduce Abeta deposition, and increase synaptic immunoreactivity. Neurobiol Learn Mem 2007; 88: 277-294. 
187. Berardi N, Braschi C, Capsoni S, Cattaneo A, Maffei L. Environmental enrichment delays the onset of memory deficits and reduces neuropathological hallmarks in a mouse mode of Alzheimer-like neurodegeneration. J Alzheimers Dis 2007; 11: 359-370.

188. Jankowsky JL, Xu G, Fromholt D, Gonzales V, Borchelt DR. Environmental enrichment exacerbates amyloid plaque formation in a transgenic mouse model of Alzheime disease. J Neuropathol Exp Neurol 2003; 62: 1220-1227.

189. Lazarov O, Robinson J, Tang YP, Hairston IS, Korade-Mirnics Z, Lee VM et al. Environmental enrichment reduces Abeta levels and amyloid deposition in transgenic mice. Cell 2005; 120: 701-713.

190. Ambree O, Leimer U, Herring A, Gortz N, Sachser N, Heneka MT et al. Reduction of amyloid angiopathy and Abeta plaque burden after enriched housing in TgCRND8 mice: involvement of multiple pathways. Am J Pathol 2006; 169: 544-552.

191. Mirochnic S, Wolf S, Staufenbiel M, Kempermann G. Age effects on the regulation of adult hippocampal neurogenesis by physical activity and environmental enrichment in the APP23 mouse model of Alzheimer disease. Hippocampus 2009; 19: 1008-1018.

192. Feng R, Rampon C, Tang YP, Shrom D, Jin J, Kyin M et al. Deficient neurogenesis in forebrain-specific presenilin-1 knockout mice is associated with reduced clearance of hippocampal memory traces. Neuron 2001; 32: 911-926

193. Wen PH, Hof PR, Chen X, Gluck K, Austin G, Younkin SG et al. The presenilin-1 familial Alzheimer disease mutant P117L impairs neurogenesis in the hippocampus of adult mice. Exp Neurol 2004; 188: 224-237.

194. Choi SH, Veeraraghavalu K, Lazarov O, Marler S, Ransohoff RM, Ramirez JM et al. Noncell-autonomous effects of presenilin 1 variants on enrichment-mediated hippocampa progenitor cell proliferation and differentiation. Neuron 2008; 59: 568-580.
195. Herring A, Ambree O, Tomm M, Habermann H, Sachser N, Paulus W et al. Environmental enrichment enhances cellular plasticity in transgenic mice with Alzheimer-like pathology. Exp Neurol 2009; 216: 184-192.

196. Herring A, Yasin H, Ambree O, Sachser N, Paulus W, Keyvani K. Environmental enrichment counteracts Alzheimer's neurovascular dysfunction in TgCRND8 mice. Brain Pathol 2008; 18: 32-39.

197. Herring A, Blome M, Ambree O, Sachser N, Paulus W, Keyvani K. Reduction of cerebral oxidative stress following environmental enrichment in mice with Alzheimer-like pathology. Brain Pathol 2009. e-pub ahead of print.

198. Katzman R. Education and the prevalence of dementia and Alzheimer's disease. Neurology 1993; 43: 13-20.

199. Laurin D, Verreault R, Lindsay J, MacPherson K, Rockwood K. Physical activity and risk of cognitive impairment and dementia in elderly persons. Arch Neurol 2001; 58: 498-504.

200. Fratiglioni L, Paillard-Borg S, Winblad B. An active and socially integrated lifestyle in late life might protect against dementia. Lancet Neurol 2004; 3: 343-353.

201. Marx J. Alzheimer's disease. Play and exercise protect mouse brain from amyloid buildup. Science 2005; 307: 1547.

202. Podewils LJ, Guallar E, Kuller LH, Fried LP, Lopez OL, Carlson M et al. Physical activity, APOE genotype, and dementia risk: findings from the Cardiovascular Health Cognition Study. Am J Epidemiol 2005; 161: 639-651.

203. Kramer AF, Erickson KI, Colcombe SJ. Exercise, cognition, and the aging brain. J Appl Physiol 2006; 101: 1237-1242.

204. Kramer AF, Erickson KI. Capitalizing on cortical plasticity: influence of physical activity on cognition and brain function. Trends Cogn Sci 2007; 11: 342-348. 